\title{
HealthSpot: Analysis of a Bankruptcy in Kiosk-based Telehealth
}

Rajeev Mudumba

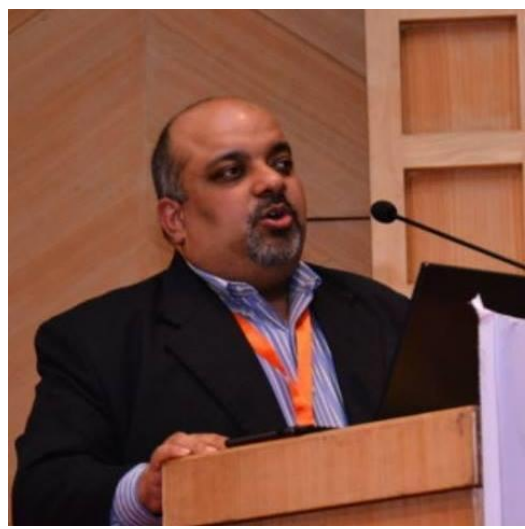

Editor's note: Mr. Mudumba was awarded the Telehealth and Medicine Today Publisher's Award for Best Article in 2016, from Tory Cenaj during the 2017 Telehealth and Medicine Today-sponsored conference, Profitable, Scalable \& Sustainable Tactics Transforming Long-term Care in Telehealth and Medicine. It is with pleasure that we reprint his analysis here.

HealthSpot, Inc., the kiosk-based telehealth services provider founded in Dublin, Ohio in 2010 had raised about $\$ 46.7$ million in several rounds of venture funding and debt capital since its inception. Among its funders, Xerox aspired to combine its BPO (business process outsourcing) knowledge with HealthSpot's software platform and also serve as HealthSpot's BPO provider. HealthSpot went on to find other partners: MetroHealth; Mayo Health; Kaiser Permanente; the Cleveland Clinic, and University Hospitals; and Rite Aid (the third largest retail drugstore chain in the country) among others. But, despite the capital it raised and the name brand partners it brought together, HealthSpot closed up shop in December 2015.

HealthSpot's 40, 8' X 5' fully enclosed kiosks came equipped with proprietary cloudbased software, high definition video conferencing, and interactive medical devices- 
specifically a blood pressure cuff, thermometer, stethoscope, dermoscope, and otoscope, as well as a built-in weight scale. HealthSpot was also working with Samsung to bring its "lab-on-a-chip" (microfluidic chips) technology to its kiosks, 1 which allowed patients to have blood tests done for cholesterol, diabetes and liver function in as little as seven minutes. Patients could engage with physicians for non-emergency condition diagnosis, health checkups, etc. For physician support, HealthSpot partnered with health networks. HealthSpot kiosks had the ability to facilitate patient-provider face-toface consultation through video conferencing, allowed for creation and tracking of treatment plans and follow-up schedules, associated medical records and transmittal of electronic prescriptions.

\section{What Went Wrong?}

Today, telehealth is portrayed as the elixir of healthcare access and cost woes. So, HealthSpot's debacle comes as a surprise.

With brand name funders and partners plus seemingly state-of-the-art technology, several questions arise as to HealthSpot's declaration of bankruptcy and liquidation.

- Was HealthSpot mismanaged?

- Were their kiosks old school in a world of internet-based ubiquitous telehealth access?

- Was their technology not cutting edge?

- Did they pursue a wrong revenue model?

In recent times, where telehealth is portrayed as the elixir of healthcare access and cost woes, HealthSpot's debacle comes as a surprise. For instance, Teladoc, the nation's first and largest provider of telehealth services recently announced the acquisition of HealthiestYou, another wellness/ telehealth provider, for a cash and stock deal of $\$ 125$ million. HealthiestYou, founded in 2012 went on to raise $\$ 30.1$ million and did $\$ 10$ million in revenues in 2015 and through the first half of 2016, did about \$8 million. ?

On the contrary, according to HealthSpot's bankruptcy filing; over the last three years, the company generated $\$ 1.1$ million in revenue of which $\$ 223,000$ was in 2014 and 
$\$ 600,000$ in $2015 . \underline{3}$

Several issues potentially confounded HealthSpot and offer learning opportunities for others in the telemedicine field.

\section{Time to Market}

Did HealthSpot spend too long just proving their kiosks' functionality in academic surroundings rather than vetting their business model in the market to bring in revenues early on? If they had spent more time on business viability early on they would have had the time to zero in on a revenue model that would have worked for them.

Other big names in the telehealth space include Doctor-on-Demand, MDLive, VSee, American Well, CSI Health Systems, Glooko, higi, and Pursuant Health. Some of these companies offer a health kiosk model and continue to grow their businesses.

\section{Technology and Business Model}

Telehealth is about providing a rock-solid, innovative technology platform, bringing in the right mix of clinical expertise, and finally, engaging consumers to take advantage of the solution. Typical revenue models include a per visit fee or a per member per month fee or both. In the case of HealthSpot, there was the additional investment for building the kiosks. HealthSpot reported $\$ 5.17$ million in assets and $\$ 23.27$ million in liabilities. Of the assets, $\$ 3.5$ million was inventory, which included 137 kiosks in storage. 4 Perhaps the process of building kiosks could have been streamlined further over time to mitigate the cost of building them.

However, as I stated before, there are other telehealth providers with a business model for kiosks that are doing relatively well. The difference could be providing access to telehealth on demand versus not. In the case of HealthSpot, it was not.

HealthSpot required its customers to have pre-scheduled appointments with physicians before availing themselves of services a HealthSpot's kiosk. This goes against the utility 
aspect of telehealth, which is about reaching a doctor remotely as and when needed. Telehealth competes against urgent care centers that do not require pre-scheduled appointments in order to gain access to more services as needed.

HealthSpot also positioned itself as a contender against other telehealth software platforms. I believe they could have pursued both models instead of alienating themselves against the ubiquitous internet-based telehealth software. Telehealth is about access through mobile as well as web technologies. Why not permit patients wherever they are to interact with physicians? Then, in case the patient requires access to the many services that kiosks offer, have them get to one at their convenience?

\section{Scale}

Telehealth is also about scale — the need to make access available to a wider population while touting its advantages, of which cost is very minor. With about 50 or so kiosks set up for use, HealthSpot had not yet planed for scaling. With the funds raised, they could have setup hundreds of kiosks to blanket their markets and spread the word to target audiences for optimal use of their facilities. This could have provided a stimulus towards decent revenues.

Telehealth services could also extend beyond urgent care to include management of chronic care and specific case follow-up, in association, of course, with the right partners for seamless workflow management. Telehealth companies are now also pushing into "telepsychiatry" frontiers by getting into mental health.

\section{In Summary}

The mobile health market is anticipated to grow to $\$ 86.6$ billion by 2020 , a yearly increase of $20.8 \%$ over a five-year period, according to Kalorama Information. $\frac{5}{\text { That }}$ is definitely a growing market with much promise and an increasing number of innovative companies crowding the space.

HealthSpot's failure offers several lessons. Most important, current telehealth players, 
as well as those entering the space, must devise a multi-pronged business and product strategy that takes advantage of every opportunity this space has to offer and in return, offer best in class services to end consumers.

Rajeev Mudumba is a health \& wellness executive, entrepreneur and investor/ advisor. Mr. Mudumba has over 20 years of leadership experience in health \& wellness and human capital management. Over the years, he has helped several payers; employers and brokers define innovative and compliant product and business strategies. Follow Rajeev on Twitter@hifromraj

Tags: BPO, business process outsourcing, cutting edge, HealthSpot, how does telehealth enhance the doctor patient relationship, lab-on-a-chip, Rajeev Mudumba, revenue model, technology platform, telehealth and telemedicine, telemedicine kiosk, telemedicine process improvement, telemedicine program implementation, telemedicine remote health, what is telemedicine and how does it work

References:

1. Samiei E, Tabrizian M, Hoorfar M. A review of digital microfluidics as portable platforms for lab-on a-chip applications. Lab Chip. 2016 Jul7;16(13):2376-96.

2. Teledoc to acquire Healthiest You. 2016. URL:

https://www.teladoc.com/news/2016/06/30/teladoc-to-acquire-healthiestyou/. Accessed 7/25/16.

3. Modern Healthcare. HealthSpot's assets are up for sale. 2016. URL: http://www.modernhealthcare.com/article/20160314/NEWS/160319963. Accessed 7/25/16.

4. Pai A. HealthSpot files for bankruptcy to pay creditors. Mobi Health News. 2016. URL: http://mobihealthnews.com/content/healthspot-files-bankruptcy-liquidation-pay-creditors. Accessed 7/25/16.

5. MarketResearch.com. mhealth Markets Worldwide. Kalorama Information, Rockville, MD. 2016. URL: http://www.marketresearch.com/Kalorama-Information-v767/mhealth- 
1674, Mudumba. HealthSpot https://doi.org/10.30953/tmt.v2.11

Page 6 of 6

Worldwide-9138421/?progid=88153. Accessed 7/25/16. 